\title{
Childhood Gliomatosis Cerebri
}

National Cancer Institute

\section{Source}

National Cancer Institute. Childhood Gliomatosis Cerebri. NCI Thesaurus. Code C114969.

Gliomatosis cerebri that occurs during childhood. 